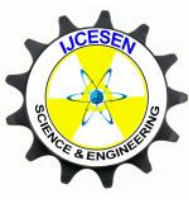

Copyright (C) IJCESEN
International Journal of Computational and

Experimental $\boldsymbol{S}$ cience and Engineering

(IJCESEN)

Vol. 4-No.3 (2018) pp. 30-33

http://dergipark.gov.tr/ijcesen

Research Article

\title{
Effect of Stress Sensitivity on Production of Tight Heterogeneous Reservoir
}

\author{
Nai CAO, Hong LI, Mengyun LIU*
}

Department of Petroleum Engineering, China University of Petroleum (Beijing), 102249, Beijing-China

* Corresponding Author : star_lmy@vip.163.com

ORCID: 0000-0003-3396-7552

\section{Article Info:}

DOI: $10.22399 /$ ijcesen.444575

Received : 17 July 2018

Accepted : 16 November 2018

\section{Keywords}

Tight reservoirs

Stress sensitivity

Heterogeneity

Production analysis

\begin{abstract}
$\underline{\text { Abstract: }}$
Permeability can be effected by many factors including effective stress, and this will further impact the final production of oil and gas. In this work, a stressdependent permeability calculation model was adopted and based on which a production function for heterogeneous tight sandstone reservoir on core scale is derived. Stress sensitivity has been taken as the primary influencing factor to analysis the impact of effective stress on the productivity of heterogeneous tight sandstone reservoir. The results shows that the stress sensitivity needed to be taken into cosideration when the effective stress cannot be overlooked in the design of developing plan for tight reservoirs; and the severity of the heterogeneity has a noticeable influence on the production.
\end{abstract}

\section{Introduction}

Heterogeneous tight reservoirs are important target areas for oil and gas exploration, many researches on the relationship between reservoir physical parameters and effective stress has been conducted with a large number of experiments[1-3]. The strong heterogeneity of tight reservoirs affects the variation of permeability, leading to different extents of stress sensitivity. Permeability is an important parameter in the calculation of production, meaning the stress sensitivity of heterogeneous reservoirs has an effect on production. It is significant for the development of tight heterogeneous reservoirs to calculate the production considering stress sensitivity. Many scholars have theoretically studied the law of stress sensitivity of permeability. Liu et al studied the variation of porosity and permeability of low permeability reservoirs with effective stress by the model of variable diameter capillary bundle [4]. Based on the characteristics of rock pore structure and particle contact deformation, Dong et al quantitatively analyzed the stress sensitivity of tight sandstone [5]. Wang et al analyzed the stress sensitivity of low permeability reservoir using the model of unequal diameter circuitous capillary bundle according to the theory of elastic mechanical thick wall tube [6]. However, most of the studies were deduced under homogeneous conditions, rather than heterogeneous conditions [7-8]. Therefore, in this paper, the production equation was obtained based on heterogeneous stress sensitivity model by Hertz contact deformation principle [9-12]. The results of different production pressure were compared between the two groups of cores.

\section{Production model}

Assuming the pores of heterogeneous tight sandstone capillary tubes are composed by particles with different properties. The basic stacking unit is a tight accumulation of 4 particles. Particles are deformed by the effect of effective stress, which leads to deformation of the pores of the capillary tube. The variation law of porosity recovery rate and permeability recovery rate with effective stress are obtained by calculating the seepage area of pores before and after deformation. The equations for porosity recovery rate and permeability recovery rate are as follows [9]:

$$
\begin{gathered}
\frac{\Phi^{\prime}}{\Phi}=\left[1-\frac{\sqrt{S(R, \sigma)}-\sqrt{S^{\prime}(R, \sigma)}}{\sqrt{S(R, \sigma)}}\right]^{3}=\left[\frac{\sqrt{S^{\prime}(R, \sigma)}}{\sqrt{S(R, \sigma)}}\right]^{\frac{3}{2}} \\
\frac{K^{\prime}}{K}=\frac{\Phi^{\prime} S^{\prime}(R, \sigma)}{\Phi S(R, \sigma)}=\left[\frac{S^{\prime}(R, \sigma)}{S(R, \sigma)}\right]^{\frac{5}{2}}
\end{gathered}
$$


Where $\Phi^{\prime}$ is porosity after deformation; $\Phi$ porosity before deformation; $S^{\prime}$ is the seepage area after deformation; $S$ is seepage area before deformation; $R$ is radiu of particle; $\sigma$ is effective stress on the pores of the capillary tube. $K^{\prime}$ is permeability after deformation; $K$ is permeability before deformation. Therefore, the production equation can be dereived from Darcy theory as:

$$
Q=\frac{K^{\prime} A \Delta P}{\mu L}=\left[\frac{S^{\prime}(R, \sigma)}{S(R, \sigma)}\right]^{\frac{2}{5}} \frac{K A \Delta P}{\mu L}
$$

Where $Q$ is production; A is the area of the overcurrent cross section; $\mathrm{L}$ is the length of the rock in the flow direction; $\Delta P$ is the pressure difference between the two ends of the rock in the flow direction; $\mu$ is dynamic viscosity of the fluid.

\section{Model Calculation}

Two groups of capillary tube pores composed by different particle size particles were selected, the rock particles Poisson ratio were 0.22 , and the elastic modulus was $12.9 \mathrm{GPa}$. The pore size ratio of each group of capillary tubes was $4: 3$ respectively $(0.20$ mm:0.15 mm) and 5:3 (0.25 mm:0.15 mm) [9]. Different particle size ratios can represent different heterogeneity of tight reservoirs. Hata! Başvuru kaynağı bulunamadı. is the relationship between effective stress and permeability of cores with different particle size ratios. With the increase of effective stress, the sensitivity of permeability stress is obvious.

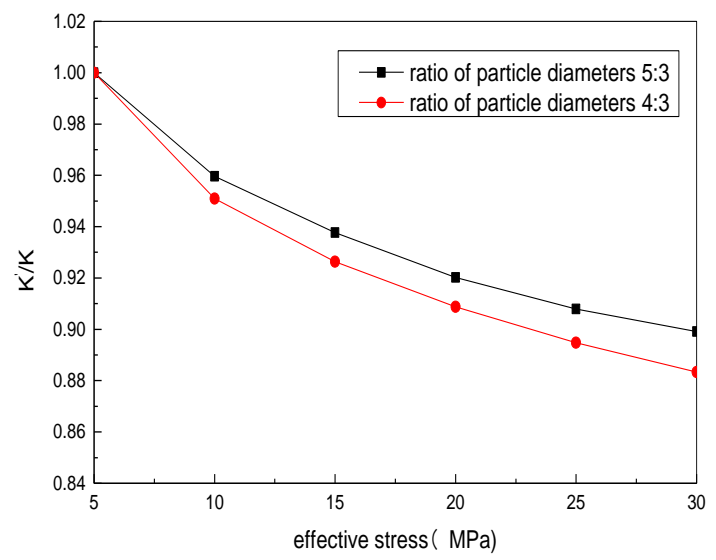

Figure 1. Relationship between effective stress and permeability of different particles formed capillaries

Table 1. Basic parameters of cores

\begin{tabular}{|l|l|l|}
\hline Parameters & Core 1 & Core 2 \\
\hline Diameter/mm & 25 & 25 \\
\hline Length/mm & 41.22 & 43.96 \\
\hline Porosity/\% & 15 & 14.18 \\
\hline Permeability $/ 10^{-3} \mu^{2}$ & 9.83 & 2.47 \\
\hline
\end{tabular}

Stress dependent permeability experiments have been conducted on 2 tight heterogeneous sandstone cores. Parameters are shown in Table1. Production prediction can be obtained by the production equation (3). The modified production under different production pressure (5-25 Mpa) has been calculated. The production results of core 1 are shown in Figure 2, the production results of core 2 are shown in Figure 3.

\section{Results and discussion}

As it can be seen from Figure 2 and 3, under the same effective stress, production increases with the increase of production pressure. Under the same production pressure, the production decreases with the increase of effective stress. However, the trend of this decline is increasing with the increase of effective stress. That is to say, the effect on production is small when the effective stress is low, but the effect is obvious when the effective stress can not be ignored. This means that the effect of stress sensitivity must be taken into account in the calculation of production for low permeability heterogeneous reservoirs when the effective stress is relatively high. Otherwise, there will be a great deviation in the calculation of production and the formulation of production systems.

Then compare the effects of different ratios of particle diameters from Figure 4. Due to the relatively small ratio of particle diameters, under the same effective stress, the lower recovery rate of permeability, the more obvious the stress sensitivity. As a result, the production is lower.

\section{Conclusions}

In this paper, a production calculation function has been derived on previous work, and production prediction on core scale has been made using it. Based on the work presented, the following coclusion can be drawn: The stress sensitivity needed to be taken into cosideration when the effective stress cannot be overlooked in the design of developing plan for tight reservoirs; and the severity of the heterogeneity has a noticeable influence on the production. 


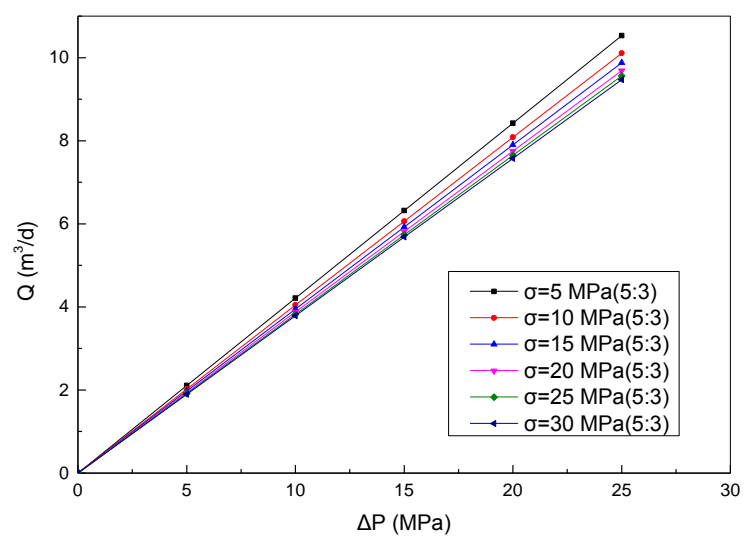

(a) ratio of particle diameters (5:3)

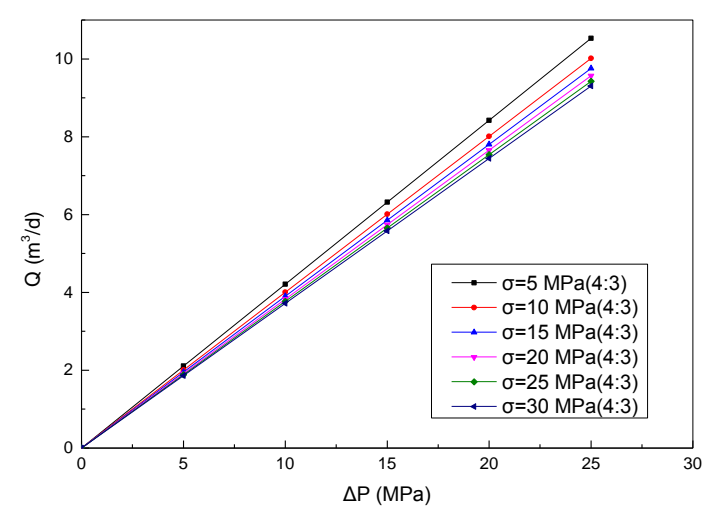

(b) ratio of particle diameters(4:3)

Figure 2. The production results of core 1

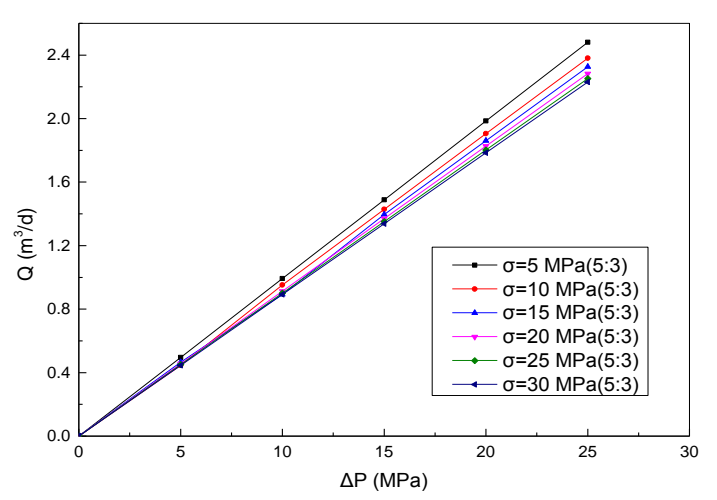

(a) ratio of particle diameters (5:3)

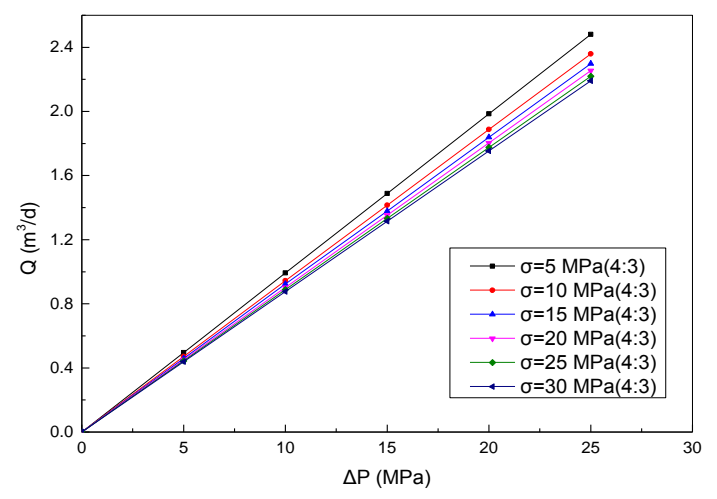

(b) ratio of particle diameters $(4: 3)$

Figure 3. The production results of core 2

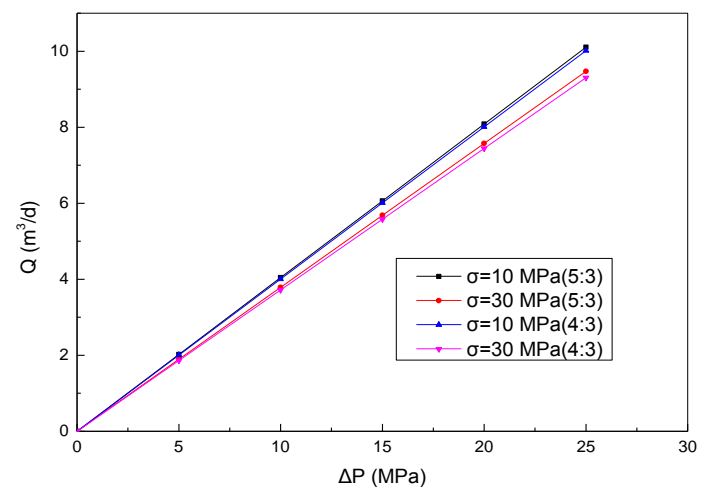

Figure 4. Comparison production results of different particle diameters ratio

\section{Acknowledgement}

The authors are grateful for financial support from the State Major Science and Technology Special Project of China during the 13th Five-Year Plan (Grant 2016ZX05014-004).This paper has been presented in "4rd International Conference on Computational and Experimental Science and Engineering (ICCESEN-2017)"

\section{References}

[1] P.X. Wang, R.J. Liu. Universal model of stress sensitive coefficient for low permeability reservoir. Petroleum Geology and Recovery Efficiency, 2012 19: 75-77.

[2] J. Gao, J. Lü, J.L. Wang. Evaluation on stress sensibility of low permeability rock under reservoir condition. Chinese Journal of Rock Mechanics and Engineering, 2009, 28: 3 899-3902.

[3] Song, X.N. Cui, X. Su, et al. Determination and application of reasonable flowing pressure in ultralow permeability reservoirs, peripheral Daqing.Special Oil \& Gas Reservoirs, 2014, 21:102105.

[4] R.J. Liu, H.Q. Liu, H.L. Zhang, et al. Study of stress sensitivity and its influence on oil development in low permeability reservoir. Chinese Journal of Rock Mechanics and Engineering, 2011, 30:2697-2702.

[5] P.C. Dong, G. Lei, B.Y. Ji, et al. Nonlinear seepage regularity of tight sandstone reservoirs with consideration of medium deformation. Chinese Journal of Rock Mechanics and Engineering, 2013, 32: 3 187-3 196.

[6] X.W. Wang, Y.Z. Huang, Z.M. Yang. Study of stress sensitivity of tight reservoir. Rock and Soil Mechanics, 2010, 31:182-186.

[7] L.Q. Wang, H.Q. Liu, S.G. Zhen, et al.Quantitative research on stress sensitivity of low permeability reservoir. Acta Petrolei Sinica, 2009,30:96-99. 
[8] X.Q. Tan, X.A. A. Yue, X.Y. Liu, et al. Stress sensitivity of low permeability heterogeneous reservoir and its influences on fluid distributiontaking CO2-drive oil reservoir as example. Petroleum Geology and Recovery Efficiency, 2009, 16: 92-94.

[9] G. Lei, H. Wang, P.C. Dong, Quantitative analysis on stress sensitivity of heterogeneous tight sandstone, 2015, 22: 90-94.

[10] M. Cevri, D. Üstü. Prediction of the Probabilities of the Transmission of Genetic Traits within Bayesian Logical Inference (ICCESEN 2016).

[11] N.M. Özgül, M.Y. Savaşçin, İ. Özkan. (2016) Recycling of Coal Ash in Production of Low Density Masonry Unit (ICCESEN 2016).

[12] M.C. Boz, F. Öner, B. Mavi. (2016) Natural Radioactivity and Radiation Hazards in Coals Extracted in Amasya, Turkey (ICCESEN 2016). 